\title{
Cognitive Socio-political Language Learning Theory, Multiple Input-output Hypothesis and Competitive Team-based Learning
}

\author{
Seyed Mohammad Hassan Hosseini \\ Freelance educator/researcher, Iran
}

\begin{abstract}
The practical results of innovative methods/approaches to teaching like Cooperative Learning (CL), which have been formulated based on constructivists' theories, are falling short of expectation in the present world circumstances. This is because they cannot reflect the realities of the real world and as a consequence have contributed to uncivilised and even maimed societies. As their ancestors, thereby, these so-called innovative interactive methods and approaches are doomed to failure. This article, as such, gives a brief but to the point introduction to the author's seminal holistic approach to teaching namely Competitive Team-Based Learning (CTBL), which has been put forward as a significant alternative to the present methods and approaches. Most importantly, the author sheds light on his approach's theoretical foundations, which consider language as a liberating agent, and distinguishes it from other innovative methods/approaches like Communicative Language Teaching (CLT). The results of some researches on the effectiveness of Dr Hosseini's didactic catalyst/weapon (i.e., CTBL) have also found a place in this article for the benefit of researchers/educators, who have also been provided with some significant suggestions. Teachers' accountabilities in classes run through CTBL have also been explicated.
\end{abstract}

Index Terms - cognitive socio-political language learning theory, multiple input-output hypothesis, competitive team-based learning, didactic weapon, language as a liberating agent

\section{INTRODUCTION}

In sharp contrast with democratic and civilized societies whose education systems are liberating agents that contribute to the prosperity of their people, dictatorial regimes' education systems are, indeed, mediational artefacts for exploiting people. To put it another way, the latter societies' educational regimes are designed in such a way that their outputs are citizens who lack socio-political awareness, critical thinking/sensibility and some other such crucial habits of mind. This kind of citizens are, in point of actual fact, blind slaves of the powerful minority as they see the world through THEIR eyes, do what THEY dictate to them, and accept THEIR dominance and strong control over their existence throughout their lives. To justify such claims, it should be reminded that before entering schools, our children tend to think critically, ask purposeful big questions, take risk, and go beyond the red lines, at least in the course of thinking. But after they graduate from schools and even universities, they lack this kind of characteristics as they have already been transformed into sheep-in-nature reticent adaptable-to-the-world recipients/objects who tend to be blind imitators and followers of their leaders. And this is exactly what THEY have designed their education regimes for!

Here in the Middle East, as in some other parts of the world, people are suffering from a number of socio-cultural, economical and particularly political problems, the root to which is our regimes of education. In addition to academic calamity, the present imperialist mode of educational regime is contributing to an increment in some socio-cultural as well as political disasters. In Iran, for instance, at least 30\% of students leave schools and universities before they obtain their certificates and degrees. Upsurge in complicated crimes, robberies, broken lives, suicides, and more importantly emergence of diverse destructive ideologies and of course divorce of Islam and brain drain may be considered as some other hazardous by-products of our purposefully ill-designed dictatorial didactic regimes, the ultimate products of which are maimed societies, dictatorship, and eventually anarchism. It is in such a circumstance that instead of focusing on bringing about a thorough overhauling of the present antediluvian instructional regimes, which have already failed to bring their practitioners effective learning, values, and skills for personal and moral development (Hosseini, 2010), our rulers are recalibrating their attention towards developing their military force/power for threatening their unsatisfied and angry people. Needless to say that our rulers do not embrace or even tolerate any form of reform, particularly in the arena of education, as they are well aware of the fact that such reforms endangers their existence. This is, as noted, because of the bitter truth that it is through their psychological tool (i.e., Education system) that they have enabled themselves to establish their favourable culture for controlling their possessions' (people) thinking, beliefs, outlooks, and behaviours. What worsens the circumstances here in Iran is that as opposed to Shah's (i.e., our previous King) era when only those opposing his dictatorial regime were at risk, in our Mullahs' era it is those opposing corruption, racism, injustice, and apartheid who are at risk! THEY even target and brutally victimize our beloved to keep us silent/slaves! See http://iranglobal.info/node/66352 
All this researcher means to say is that it is not possible to envision the contribution of these power-thirsty corrupt wolf-in-nature sheep-like politicians to their nation's prosperity - to live, humane, healthy, creative, and civilised societies and world peace. It is in such a circumstance that this researcher, as a liberal educator, thought that if students/tomorrow citizenry, who live under tyrannical/fascist regimes, had the opportunity to feel the taste of democracy, and if their teachers could contribute to empowering and turbo charging their minds with critical approaches to analytical and divergent thinking skills, then they would willingly and systematically take the course of action against totalitarianism/corrupt regimes. This researcher, thereby, as an agent of change, designed and developed his didactic catalyst/weapon (i.e., CTBL) based on his own edu-political theories in order to operationalise his dreams. He suggests the implementation of his seminal liberal approach to democratic education (CTBL), to teachers/educators particularly in dictatorial regimes in order to enable them to orchestrate/facilitate a peaceful shift to democracy in their countries.

\section{Competitive TeAm-BASEd LeARning: Dr Hosseini's (This ReSEARCHER'S) EduCATIONAL WeAPON}

Before continuing our discussion, please watch the 17-minute video of this researcher's introduction to his educational weapon at https://youtu.be/cPtOUaIkJlk or at http://www.aparat.com/v/i32tK. As this researcher (Hosseini, 2010) has confirmed, CTBL is a holistic contextualized approach to teaching and learning that reflects the real world holism. It tries to produce a more realistic depiction of the real-world norms and settings in the classroom, as the microcosm, in order to more effectively connect learners to the real world, the macrocosm (Hosseini, 2014). As explained in the above video, the procedure for presenting a unit/lesson, in CTBL classes, follows a regular systematic cycle through two phases each of which incorporates five main components. It is such multi-layered mechanisms underlying CTBL settings, which is enriched with an atmosphere of ambiguity, doubt, and conflict, that provides an ideal matrix for group discussion and interaction and outpouring of the variety of opinions, strategies, thoughts, ideas, and of course solutions to problems. Another characteristic of CTBL which distinguishes it from the present cooperative learning (CL) methods and approaches refers to the fact that competition, in classes run through CTBL, is encouraged among teams via different mechanisms, chief among which is its evaluation system. Competition among teams, by its turn, contributes to further involvement and co-operation of team members with one another too. Another focus area of CTBL's special evaluation system is on bringing individual responsibility among all team members, which has been neglected by the present CL methods and approaches. As it has been shown in the video, the procedure in classes run through CTBL is not a loose anything goes one as it is with other so-called innovative interactive methods and approaches. It is highly structured, purposeful, strategic, and effective.

\section{Competitive Team-based Learning and Teachers' Accountabilities}

If one attempts to construe the philosophy beyond the politics of education systems implicit in today education, we may, this researcher reckons, discover certain mysterious shocking principles:

1. To talking to/lecturing and dictating from the above in contrive environments, which contribute to negation of negotiation/discussion and encourage passivity, is opposed talking with in semi/authentic environments which encourage democratically learning/living, collaboration, contribution, and development;

2. To learning through survival skills and stratagems in order to pass the course and get a degree towards a dream job is opposed real learning, practicality, and usefulness;

3. To repeating, parroting back and syllogistic reasoning is in sharp contrast to the development of metacognition and critical and creative thinking which are the essential requirements for mind empowerment and emancipation of the Other;

4. To training students to be blind slaves for Capitalism is in direct contradiction to humanitarian principles;

5. To insisting upon antediluvian syllabi and textbooks is opposed having integrity in serving God's ends;

6. To envisaging the future based on Hitlerian outlooks is opposed building sustainable futures based on the realities of tomorrow, and

7. To learning from experiences and passively acting is opposed learning from reflecting upon experiences and proactively strategic reacting.

In the current scenario of ongoing globalisation, which is highly multicultural, incredibly complicated, and of course developmentally and fiercely competitive, teachers need to view their tasks from a more panoramic perspective which, in its turn, solicits an understanding of pedagogical and socio-political objectives and commitments. As educational goals are being broadened to include teaching metacognitive knowledge, higher level thinking and reasoning skills, and problem solving for successful life-long learning, interaction, working, and living, new challenging expectations and multifarious roles and responsibilities are being expected from the present world teachers. Today teachers are expected to play key roles in ensuring not only true learning and academic success of students but also the development of humane and compassionate societies and civilizations. This is possible via CTBL as it suggests teaching tomorrow citizenry humanitarian ways of interaction, co-operation, competition, and living.

Teachers, in CTBL settings, have plenty of opportunities to plant, nurture, and develop human values, morals, and attitudes in their wards, who are tomorrow's citizens of the globe. Below are some related pro-social and life-long learning and interaction skills and strategies, which reflect the needs of working and living in today world context, emphasised by this researcher: 
1. The ability to listen and to be flexible in thinking in order to be able to consider each and every person, idea, philosophy, etc. objectively first, in such a way as if it were new (i.e., the ability not to be adversely influenced by preceding impressions);

2. The ability to bear a responsibility to others and develop and consider different solutions to problems at hand;

3. The ability to gather the relevant information from among the ocean of irrelevant and at times false information;

4. The ability to communicate precisely and effectively;

5. The ability to think creatively and critically but rationally, strategically, and efficiently in order to be able to realise facts from among diverse information, opinions, and ideas;

6. The ability to criticise effectively, with reason, logic, and evidence;

7. The ability to manage conflicts peacefully and make collective sound decisions about personal and civic affairs, in real-world settings;

8. The ability to refuse to accept false conclusions;

9. The ability and the courage to fight the battle against any sources of hegemonic ideas, condescending looks, Hitlerian outlooks, repression, corruption, and destruction, and

10. The ability to generate 'the truth' throughout the world as it would contribute to the emancipation of the Oppressed majority, who are almost always the majority but marginalized in our societies.

These are part of the reasons as to why this researcher is of the stand that teaching, particularly in today world context of anxiety, racism, oppression, corruption, and destruction is more than science: It is, and must be appreciated as, an art which involves a very complicated 'socio-political process'. Therefore, teachers who would like to employ CTBL for the sake of it's magic transforming power should be willing to convert themselves first if they want to reap the target results out of it's implementation. A thorough understanding of CTBL's spirit, its origin, objectives, etc. would give them the willpower and the courage to transform themselves into intellectual agents of critical awareness, attitudinal change, and social disorder and, in short, CHANGE; change in cognition, thinking styles, beliefs, attitudes, and actions of the inhabitants of their milieus, for uprooting apartheid, fascism, and dictatorship from among their societies. This way, they could contribute to security, development, and peace in their societies and consequently in the world.

To such ends, teachers should first and foremost know that the success of CTBL, as any other pedagogical practice, is essentially accompanied with the kind of relationship they have with the learners. As this researcher (Hosseini, 2009, 2010) has explicated, in CTBL classes, they should adapt integrative rather than dominating roles if they want to bolster the status quo inherent in CTBL settings more effectively. This is because leaders who adapt autocratic roles ignore and even disregard the judgment and desires of their people and convey the idea that they are nothing but objects/animals. Such groups of teachers also, knowingly or unwittingly, not only obstruct the process of growth in their people but, in the long run, contribute to dictatorship, the ultimate result of which is anarchism. This is by virtue of the fact that although authoritarianism, as Freire (1973) also eloquently confirmed, 'leads to apathy, excessive obedience, uncritical conformity, lack of resistance against authoritarian discourse, self-abnegation, and fear of freedom', it will also cause people to adopt 'rebellious positions, defiant of any limit, discipline, or authority'. Teachers who are integrative in behaviour, on the other hand, are open-ended in their outlook, flexible and logical and, as ordinary and responsible members of their lands, try to understand their people. They are able to listen to them patiently, show genuine interest in their ideas, respond tactfully, and observe and evaluate their progress/development carefully. Such groups of leaders are able to think democratically and so are open to divergent, yet productive thoughts, and intact solutions based on the discussions, in an environment which involves mutual trust and respect. They are likewise able enough to welcome constructive criticism diplomatically - with a broad outlook, and above all evaluate and modify their own strategies of class management and leading/teaching from the authentic feedback they receive in course of their interactions with their people. Finally, they never hesitate to acknowledge/reward the value of individual suggestions and particularly constructive criticism. It is such characteristics of CTBL's teachers that encourage people to trust, and respect them and follow their instructions enthusiastically.

Another point for teachers to take heed of is that as it is context that gives meaning to content in CTBL environments, the provision of a psychologically safe social climate that reflects acceptance, care, genuineness, reciprocal and interpersonal trust, tolerance, and respect should be given top priority. It goes without saying that such atmospheres naturally impetus risk taking, giving and receiving influence, creativity, and critical thinking. Teachers, therefore, at the initial stages of conducting their courses, must explain about CTBL, define academic and social objectives and skills that students are to master and apply, discuss the learning culture, identify norms, and specify and model desired behaviours. They should also elaborate on the criteria for success and evaluation procedures for the appraisal of team and member performance. Importantly, they ought to take care of team formation and composition, the arrangement of classroom, tasks, and activities. They should structure teams and the learning tasks and class activities in such a way that they improve the cohesion of the teams and bring reciprocal meaningful interaction among team members, and encourage their individual responsibility for their own learning and the learning of their teammates, in a relaxing environment.

Teachers should also bear it in mind that they are not the predominant source of information who try to infuse knowledge into vacuumed minds as it is in traditional teacher dominated methods like the Lecture Method/the Banking 
Method through which the teachers take the role of interveners/depositors. Nor are they merely fellow facilitators of the learning process and scaffold providers as it is in the so-called innovative methods and approaches like Collaborative Learning, Interactive Learning, and the conventional methods in the arena of CL. Nor are they merely communication models and facilitators of the communication tasks for language learning as it is in CLT. But rather, they are expected to perform several roles simultaneously. Besides to the above-mentioned roles, CTBL's teachers should play their roles as dissectors, psychologists, discerners of current needs and demands, interactors, frontiers of knowledge, and most importantly models of criticism, innovation, and change. As their classes' leaders, they should be able to problemitise the learning/living contexts in such a way that it encourages doubt, negotiation, conflict, and discussion. They should also be able to play their roles as mind decolonisers, attitude re-orienters and Agents of critical awareness and social change and development. They should also be good orchestrators of opportunities for effective learning and personal growth on the part of the students. They should, at the same time, actively monitor their people behaviours, achievements, and the functioning of teams and their dynamics, and provide continuous authentic feedback on individual as well as communities'/teams' progress in order to tactically engineer and soften the learning/development process. Teachers should ensure that there are enough and equal opportunities for all team members, in their heterogeneous teams, to think, brainstorm, discuss, and solve problems collectively - in a congenial ambience. In providing assistance, they should act as midwives, who give birth to challenging ideas and knowledge in students' minds and help them to generate their knowledge and thoughts actively, critically, and creatively. All these enable teachers to bring the students' cognitive, emotional, and intellectual involvement as well as their active participation and contribution in the learning process in class activities for their comprehensive awareness, empowerment, and growth for a life-long successful learning and living.

Teachers should ensure that emphasis is laid on authentic tasks and strategy training so that internalisation occurs through scaffolding and application of new acquired knowledge and strategies, in contexts that value dialogue, which involves respect, in lieu of monologue, which involves issuing communiqués, and negation of negotiation, critical thinking and reasoning and development. Other effective variables such as vocabulary and grammar acquisition through, for example, reading of authentic texts and most important of all adhering to the CTBL culture of learning should not be neglected in language classes if teachers want to have more effective language courses via CTBL. The point is that teachers should teach the academic concepts and strategies and social norms and principles simultaneously - as a whole - in appropriate contexts (contextualised teaching) with an eye to the outside of the classroom, to the real world. Therefore, merely focusing students' attention on learning the language is never sufficient. The stratagem of 'teaching students to retell and then forget' is also strongly prohibited in CTBL settings. But rather, teachers must try their utmost to immerse the students in the learning process not merely to learn but also to learn how to learn, compete, defeat or even fail, at class and social level. Teachers need to make students be aware of the full range of tactics and strategies available to them. They could train them to learn to think about what happens during the language learning process (meta-cognition), which in turn will enable them to develop more effective learning strategies, especially monitoring strategies. But they should also raise their students' awareness of the patterns of interaction in their milieu, outside the classroom. Teachers should analyse such patterns, directly or indirectly, and shed light on their consequent effects on the condition of their students' existence. To put it another way, teachers must increase their students' socio-political awareness and contribute to their socio-political competencies. Students' reactions on the agents of such patterns in their milieu will take care of itself, in the long haul though.

As this researcher (Hosseini, 2010) has explained, at a more concrete level, at the class level, teachers should be on a constant lookout for appropriate opportunities to problemitise the learning context via posing captivating and at the same time challenging ideas or questions in order to reinforce the students meta-cognition and tap into and activate the innate skills and abilities assumed to be potentially present in them all. Teachers should posses the art and the ability of 'leading' to more effective learning and development 'by questioning' in in their lands. But the imperative point is that merely posing questions is not enough; the kind of questions teachers ask make a world of difference to, for example, the quality of ultimate results. In fact, it differentiates between inspiring people allegiance or sabotage. Therefore, teachers should be able to address challenging queries to push the edges of students' thinking and motivate a pursuit for resolution via fostering especially 'outside-the-box' thinking. Such open questioning not only give students a voice and stimulates effective and authentic discussions, but also broadcasts respect for their opinions, expertise, and communicates value. It thus lends itself well to various settings like creative problem solving, team building, more effective participation and teamwork, a successful learning ethos and direction-setting, and valuable learning/living. To be successful in CTBL classes, thereby, teachers should learn to ask genuine powerful questions that target activating the critical attitude of students' minds (critical thinking) and encourage risk taking in thinking (creative thinking). One more point of crucial importance that teachers who would like to run their classes through my instructional approach should bear in mind is that merely enabling students to answer their strategic questions is never sufficient. They need to train their wards in such a way that it ensures their power to develop pertinent questions also, if they want to influence the world. They stimulate them to more effectively and comprehensively exercise their brain cells in critical thinking and, in the process, come up with fresher, more innovative, and more powerful ideas. Asking such questions unleashes students' dammed creativity and paves the way to new opportunities and real knowledge. 
Leaders, who run their lands through CTBL, must, at the same time, also be able to diagnose and even predict the affective, cognitive, and environmental oriented problems and barriers to learning and be ready to resolve them appropriately whenever they arise. They need to know how to tackle different unpredictable problems, for example, with extremely disruptive citizens. They must be able not only to manage conflicts but to harness them to fulfill their socio-pedagogical/political goals. More specifically, they must pay special attention to low status, timid, shy, slow, and weak learners/people, and take heed of the fact that not every person can be fitted with any team.

One more thing which needs to be reminded is that because of the deficiencies in teaching English at primary and secondary levels, particularly the college teachers have another important professional challenge which must be met. They ought to fill the gaps in knowledge of students and wipe out the fossilized deterrent strategies of learning and the effects of bad learning. They should also modify their people's the sort of attitudes towards subject area, learning/living, and their milieu which if allowed to linger, they would barricade further learning and social/nation development. Teachers should also encourage citizens to participate and use English, as an international lingua franca, in their state/small team discussions with proper accent, which requires patience and strategies.

In CTBL settings, thereby, teachers must be able to think like scientists who have sufficient knowledge in the components of their profession such as subject matters, applied psycholinguistics, teaching methodology, and typologies of learners, and act like artists. They should be well informed of the principles as well as the latest issues and theoretical perspectives in the related disciplines such as social and cognitive psychology, sociology, anthropology, economics, philosophy, and particularly political science. Furthermore, they should have a comprehensive understanding of their people demands and expectations, personalities, competencies, learning/living styles, and of course the nature of learning and the contexts and processes under which it occurs more effectively. Most important of all, leaders should be cognisant of their people socio-political/cultural backgrounds and norms. It is also necessary for teachers to be adaptable and flexible enough to make the best use of the latest findings in their fields of concerns. It is, then, that they could exploit their arts to harness their knowledge for meeting CTBL pre-established objectives and goals, which is awakening and empowering tomorrow citizenry, and turbo charging their minds in such a way not only to survive in the face of untoward circumstances (occasioned by the side effects of the phenomenon of globalisation) but also to have significant impacts upon their milieu and even upon the world.

Finally, CTBL classes can also be supported through connecting learners to virtual learning environments (see Hosseini, 2007). Through developing their classes' blogs, wikies, websites, and moodles, for instance, which are supported by online technologies like podcasting and vodcasting, teachers can enhance the attainment of the CTBL's soio-political objectives. To sum up this section, it is in such a mindset about teachers' responsibilities that this researcher believes that science and art are two strong wings for teachers without either of each they cannot succeed to proceed.

\section{MAJOR TheOreticAl BuILDing Blocks OF CTBL}

\section{A. Cognitive Socio-political Language Learning Theory: Theory of Language of CTBL}

As noted, the practical results of the present interactive methods and approaches like Cooperative/Participative/Interactive Learning, which have been introduced by constructivists, are falling short of expectation in the real world situations as they are not able to mirror the real world holism. It is in such a context that this researcher believes that in addition to sociolinguistic/socio-cultural factors, economical and particularly political factors should be prioritised in (language) learning environments as they affect students' motivation and zest not only for learning but for living as well. This is the reason as to why this researcher insists on the idea that socio-political competency should be added to students' communicative competency in our classes. This researcher is of the opinion that learners are socio-politically situated- rather than isolated individuals in communities, and that language is a tool for socio-political relations and performance of socio-political transactions among individuals and communities.

In its theory of language, thereby, as this researcher (Hosseini, 2010) has explained, CTBL postulates language use and language learning as interactive activities which occur best in contexts where encourage discussion and negotiation of meaning, and learner active involvement and participation in team activities that involve risk taking, hypothesis testing, plan/decision making, problem solving, and making judgments about the achieved progress (i.e. developmental evaluation). In words of one syllable, CTBL espouses the 'interactional' view of language, the developed combination of structural and functional views of language, and so prioritises both the knowledge of appropriate use of meaningful language and the ability to manage discourse interactions, in socio-political contexts.

Therefore, as opposed to constructivists who deem language as a social phenomenon and as a means for communication and constructing knowledge, this researcher believes language is a socio-political phenomenon and a means for any form of reform and constructing just societies also. To put it another way, the truth is that language is a means for thinking as one may not be able to think without (mental/verbal) use of language. Simply put, language facilitates managing/engineering mental activities/thinking. Keeping this in mind, the point, in this researcher's view, is that thinking, which is perhaps the mere possession over which we, the oppressed, have absolute control and no one can deprive us of, is crucial not just for (language) learning to take place and for successful social interaction, it is also the very requirement, if not the key, for any form of reform, change, and transformation. (Hosseini, 2010) This is possible because thoughts gather together to shape our attitudes. And our attitudes impact upon and reorient our beliefs. And 
there is POWER in our beliefs as they influence and go forth in our behaviours and actions, which by their turn, lead on to our destinies. Thinking, thereby, this researcher reckons, is the most powerful as well as complex psychological tool or artefact for any form of reform and building organised and just societies, which better contribute to world peace. (Hosseini, 2010)

But the kind of thinking this researcher is discussing about is something totally different from the ilk of thinking the conventional instructional methods and approaches like the Traditional Lecture Method or the Banking Method are encouraging. The sort of thinking this researcher is discussing about is a complicated profession as he is of the stand that just as there is nothing easier than to think, so there is nothing more difficult than to think appropriately. The kind of thinking he suggests exacts techniques and methods, as it involves objectivity, direction, approach, style, and quality. Therefore, what is essential for this researcher's students to consider in the course of thinking is that they should try to

1. Decolonize their minds and approach new things, ideas, persons, etc. objectively first.

2. Think about not only the lines and between the lines but also beyond the lines, which exacts critical awareness.

3. Be risk takers and go beyond the red lines.

4. Think from a higher level and do not engage too much in details.

5. Think holistically, creatively, logically, critically and analytically.

The bare truth is that such sort of thinking leads us to the truth, and as holly prophet Jesus confirmed, the truth will liberate us. One hour appropriate and strategic thinking thereby is much more valuable than years blind prayer particularly for the underdogs in countries ruled by despots or some wolf-in-nature sheep-like leaders.

To sum up, from the point of view of this researcher's Cognitive Socio-Political Language Theory (CSPLL theory), language is something more than a means for merely communication. This researcher believes that language is $a$ liberating agent also as he is of the opinion that language has the potential to provide us a channel through which we have the significant opportunity to convey our ideas, ideology, dreams, beliefs and thoughts to our audience, to our students who are tomorrow citizenries. This is very important because that way we can contribute to a change in their approaches to thinking and even to a change in their thoughts. The point, as explained, is that their thoughts shape their destinies. This is as to why this researcher believes that teachers are agents of change. We, teachers, thereby, as AGENTS of CHANGE, have the potential to change our present peasant societies into more civilized nations and civilizations, through availing ourselves of the purposeful language in our classes. It was in such a context that this researcher suggested teachers to run their classes through his liberal approach to teaching which was designed based on his own CSPLL theory. You may also search Dr Hosseini Didactic Weapon on the net to see his introductory video to his innovative approach for which he received his $\mathrm{PhD}$ in language teaching methodology from the biggest democracy in the world. As mentioned, this researcher is of the stand that his educational weapon contributes effectively to the overthrow of corrupt and dictatorial regimes as it is, in point of actual fact, an approach to the education of the Oppressed.

This researcher's (Hosseini, 2010) CSPLL theory, which considers language as a liberating agent, and its affiliated approach to various forms of transformation per se could justify the reason as to why the mechanisms underlying CTBL are directed towards improving thinking abilities of students. They focus upon promoting different aspects of thinking (particularly higher order of incisive and analytical thinking) abilities of students with special attention to the significance of the process of thinking in reasoning growth. It is based on such premises that CTBL provides all students with more equal opportunities to obtain knowledge, understand it, analyse it, synthesize it, evaluate it and make judgments via the application of language (i.e., thinking) to highly motivating genuine shared learning environments, with the scaffold of their peers. (See also the section on Multiple Input-Output Hypothesis)

In CTBL bona fide environments, students have significantly more opportunities not only to listen to their more capable pairs or partners in their teams, while they are thinking aloud, which allows them to acquire their styles of and approaches to thinking, but also to use language - to think - in such contexts. Moreover, CTBL supplies students with the significant opportunities to produce/use language in more complicated contexts such as in class-wide discussions or in team tournaments wherein they are also challenged to support their answers/ideas with reason and logic (i.e. to practice purposeful thinking - by using language in the course of interaction with others). To put it another way, one outstanding feature of this researcher's approach to teaching refers to the fact that despite the present methods and approaches cherished by our antediluvian dictatorial didactic regimes, it draws on language as a tool for empowering individuals' minds with critical approaches to incisive, analytical, and divergent thinking skills in order to enable them to have greater impact on their milieu and in so doing to transform the conditions of not merely their own existence but also that of the humanity. All these are possible as it is language, in this researcher's classes, that is the instrument to think, negotiate meaning, and discuss understandings and ideas, and criticize one another for more comprehensive and effective achievement, growth, and development. Thinking, meaning, and social interaction are, thereby, appreciated as the key to successful (language) learning/living, in CTBL settings. (Hosseini, 2010)

Therefore, contrary to the traditional methods and approaches' theoretical foundations which consider language learning as a simple shallow exercise that could be learnt through passively listening, emulating, and reproducing the material already memorised in contrived environments, CTBL's theory of language deems language learning as a complicated process. This process involves active involvement of all of the students in interactive semi/authentic sociopolitical environments. Such environments are highly contributive to the development of objectivity, creativity, social skills, socio-political awareness, higher-quality cognitive strategies, and higher order of incisive and analytical thinking 
skills such as abstract thinking and critical deductive reasoning, rather than survival strategies and lower forms of mental behaviour/thinking (e.g. syllogistic reasoning).

In sum, from the point of view of CSPLL theory, language, as a socio-political phenomenon, is the cornerstone of human prosperity. That is, language develops best in interaction of individual with others, and, in its turn, contributes to their thinking/reasoning abilities. And an individual with a powerful mind, who is naturally rational, would have a more successful social relationship and would more effectively contribute to just societies and world peace. (Hosseini, 2010)

As indicated in Figure 1, in this researcher's opinion, social interaction, language development, reasoning abilities, learning, successful relationships, and social development and world peace are inextricably interwoven.

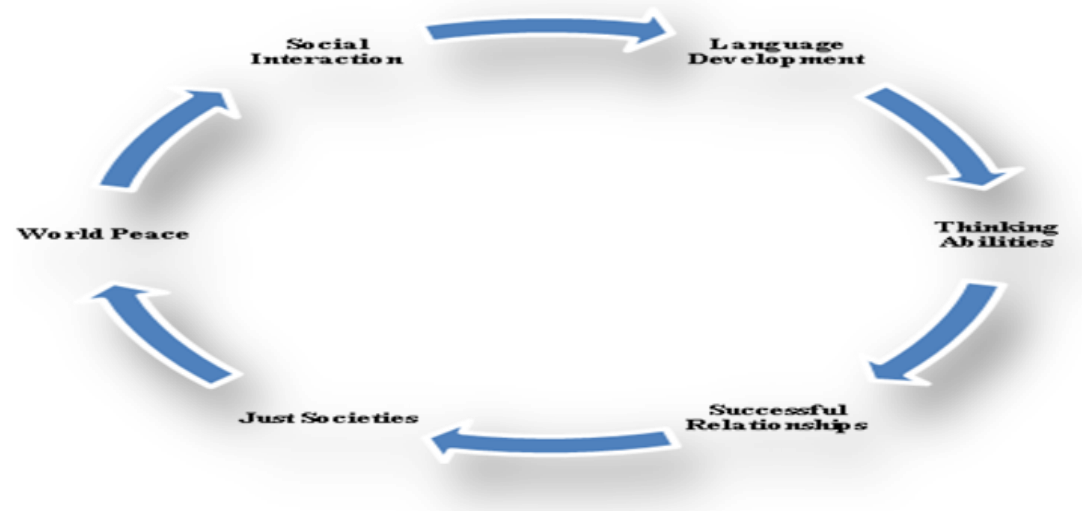

Figure 1. The cyclical interplay among social interaction, language development, thinking/reasoning abilities, learning, successful relationships, and social development and world peace proposed by CSPLL theory. (Hosseini, 2012a).

As noted in the video and in the above sections, CTBL is not limited to developing the ability of students for merely appropriate use of language and/or to focusing on communicative competence of students, as it was posited by founders of the present instructional methods and approaches like CLT. Nor does it focuses on developing merely social skills of students as it is in present innovative cooperative learning methods and approaches. CTBL has a far broader and much more realistic outlook as this researcher is of the opinion that successful survival in the present real world settings and being able to face the realities of this dynamic and complicated tough competitive world demands something more than the appropriate use of the language in benign environments (Hosseini, 2007). Through applying CTBL, teachers have enormous opportunities to impact upon thinking styles and approaches of tomorrow citizenry, improve their sociopolitical awareness, recalibrate their attitudes, redirect their beliefs and change their behaviors, all of which affects our shared destinies. Furthermore, as explained, in CTBL settings, where using the language to learn it rather than learning to use it is encouraged, students learn to take responsibility not just for their own learning in the course of constructing knowledge but for constructing just societies in the real world situation.

This researcher hopes that his theory would involve a paradigm change in the present ideological trends in the arena of Education in general and ELT in particular.

\section{B. Multiple Input-output Hypothesis: The Present Hypotheses Are Not Enough}

According to the Noticing Hypothesis, only that part of the (comprehensible) input which is noticed could find a mental home and so become intake. Let this researcher continue that this may best happen if the environment is relaxing and affective filter is low, and if interaction is encouraged. (Hosseini, 2010) To put it another way, the Noticing Hypothesis, Input Hypothesis, Affective Filter Hypothesis, and Interaction Hypothesis contribute to ELT, but they are not enough. The point is that mere intake, for the contribution to which the mentioned hypotheses have been put forward, is not adequate: Students also need to communicate their understandings (The Output Hypothesis). The problem, however, is that, as a number of researchers like Jiang (2010) have also averred, not all the intake could be transformed into productive skills (i.e. writing and speaking), albeit they more easily contribute to listening and reading abilities of students. Worse yet, to this researcher's best knowledge, there is no didactic theory or hypothesis that proposes an effective solution for contribution to this kind of transformation. This thought-provoking lacuna in the present related literature inspired this researcher (Hosseini, 2010) to propose his hypothesis, Multiple Input-Output Hypothesis (MIO hypothesis), as under, in order to address the dilemma, and in so doing to contribute to the success of ELT:

Though input, low affective filter, noticing, output, and even interaction (even as it is considered by constructivists like Vygotsky) are crucial, they are not sufficient conditions for more effective and comprehensive language acquisition to take place in language classes: Greater and more systematic focus should be on the transformation of the intake into productive skills. And the provision of multiple sources of both 'input' and 'output' in learning environments is an appropriate solution for more effective contribution to this kind of transformation. (Hosseini, 2010, p. 239) 
Realising the importance of multiple sources of input and output in language acquisition as one of the major requirements for more effective and comprehensive language learning and development, this researcher proposed the MIO hypothesis. Consequently, he (Hosseini, 2010) has tried to bring multiple sources of input and output through the implementation of a variety of activities and strategies in bona fide and highly structured motivational- as well as dialogic-based CTBL relaxing interactive environments to contribute to the explained transformation. Valuing language as a whole (i.e. integrating all facets of language, which is not appreciated in the arena of ELT today), encouraging peer discussion in different stages (i.e., through pair work, teamwork and class-wide discussions), AND appreciating the significance of multiple whos are among them.

To appreciate the integration of all (sub-) skills of language even in specific courses for reading, for instance, this researcher (Hosseini, 2010) tries to consider listening, speaking and writing as complementary skills to reading. He believes that the whole language, rather than its isolated parts, carries more meaning, which should be negotiated and processed in this researcher's classes. Furthermore, these skills have many characteristics in common, and so their effects are interrelated. The ideas in a text can contribute to more effective communication (i.e. listening and speaking), and hence the development of writing abilities of students which is in turn conducive to reading. Moreover, as this researcher (Hosseini, 2010) put it, the fact is that in order to prove their academic reading abilities, especially at the collegiate level, students need to communicate properly. These are parts of the reasons for accommodating writing activities like note taking, outlining, paraphrasing, and summarizing in learning environments that highly encourage oral negotiation of themes and ideas as complementary activities to reading in this researcher's reading classes.

These activities in such situations are conducive to further involvement and active participation and contribution of students in collaborative learning and encourage them to focus and concentrate not just on semantic but also on syntactic components of texts at hand which make learning more purposeful. Needless to say that this kind of context seeks mutual input-output treatment and also deeper analysis of both input and output not just for meaning but for accuracy and frequency as well and so solicits deeper levels of cognition. And all these, in their turn, contribute to students' in-depth comprehension of the material and also to their productive skills. These in-this researcher's-classes social activities (i.e., reading, listening, speaking and writing), thereby, not only serve his classes as multiple sources of input and output but also contribute to improving their own interwoven effects. The nature of the interactive learning situation occasioned by the appreciation of these four skills plays its role as a mediator between input and output. In sum, all these mechanisms help to turn input into understanding and understanding into output; that is, they contribute to the transformation. (Hosseini, 2010)

It goes without saying that such communicative situations provide learners with the opportunities to learn not merely about the language but also about how to use the language appropriately in semi/authentic environments. They develop students' higher-quality cognitive strategies, which in their turn contribute to productive skills and long-term retention of information, which is a criterion for real learning. (Hosseini, 2010) More importantly, such contexts are also more likely to bolster students' various aspects as well as quality of thinking abilities, in implicit and explicit ways, which are contributive to purposeful living. This researcher's MIO hypothesis is thereby a great asset to modern ELT. (Hosseini, 2010)

Apart from the theory and the hypotheses discussed in the present article, there are likewise a considerable number of theories which confirm the relevance of CTBL. Andragogy-, socio-cultural-, engagement-, speech-, motivational- and even behavioural learning- theories are among them. (See Hosseini, 2010)

\section{Distinguishing CTBL FROM CLT AND Other InTERACTIVE MethodS AND APPROACHES}

As opposed to Communicative Language Teaching (CLT), this researcher's innovative instructional approach

1. Has strong and unique theoretical foundations;

2. Supplies pragmatic guidelines to effective and systematic implementation of teamwork, which is of paramount importance for the success of language classes;

3. Systematically caters to learners with different ability ranges and learning styles;

4. Is not restricted to the PPP (Present, Practice, Produce) model of presentation as this researcher has, for instance, introduced another $\mathrm{P}$ which stands for Personalising what is learnt by the part of learners;

5. Appreciates the significance of multiple sources of input and output and some other crucial context variables like motivation and active as well as total engagement of all learners in the learning process;

6. Generates highly relaxing and at the same time motivating learning atmospheres for more effective language acquisition and learning;

7. Conveys crystal-clear views regarding the learning process and the mechanisms under which effective language learning occurs;

8. Is not limited to a particular view of language learning or a particular type of syllabus;

9. Facilitates simultaneous development of all aspects of communicative competence of students, including their socio-political competence, which has been overlooked by even modern educational theories and approaches like CLT;

10. Takes great care of moral and human values, and

11. Never forgets the idea that learners are human beings as it does not focus on merely enabling learners to communicate: CTBL is cognizant of the fact that successful living in the present real world settings and being able to 
face the realities of this dynamic and complicated competitive world demands something more than the appropriate use of the language in benign environments. (See Hosseini, 2007)

Therefore, as this researcher (Hosseini, 2014) explains, CTBL is of high value particularly for today world language classes in the sense that the mechanisms underlying it are naturally favourable not only to language acquisition and to the development of all aspects of communicative competence of students. They are also highly conducive to critical sensibility of students and the quality of their understandings and reasoning that are contributive to the accuracy of their long-term retention, personal growth, and disposition.

What is more is that contrary to the present Cooperative/Interactive Learning Methods and Approaches, CTBL

1. Helps the best students feel satisfied and puts an end to their objection and unwillingness to contribute their efforts into the success of their groups;

2. Enforces individual accountability of all group members, and thus limits the scope for social loafers and free riders;

3. Brings for students not merely a zest for true and active shared learning but further opportunities to be more clearly aware of their capacities and capabilities in a broader sense also;

4. Equips students for current globalized environment which requires workforce and citizens who are competent in skills like teamwork, conflict management, and successful collective decision making amidst competitive environments, and

5. Contributes to learning humanitarian democratic values and hence to the elimination of dictatorship and apartheid which means the development of live, humane, healthy, creative, and civilised societies and world peace. (See Hosseini, 2012, 2018)

\section{SOME RESEARCHES ON THE EFFECTIVENESS OF THIS RESEARCHER'S INSTRUCTIONAL INNOVATION}

A number of researches have illustrated the significance and effectiveness of this researcher's instructional approach, Competitive Team-Based Learning (CTBL). In his MA research study, this researcher (Hosseini, 2000) compared the effectiveness of his own approach (CTBL) with the Traditional Lecture Method (TLM). He found significant results for the effectiveness of CTBL in improving the reading comprehension of Iranian high school students. Also, he found that his approach contributed to the development of reading comprehension abilities of lower performers more effectively than the TLM.

This researcher's PhD research study (Hosseini, 2009, cited in Jahanbazian, 2015), which was a comparative empirical research study sought to explore and examine the complex effects of his educational innovation, CTBL, with Learning Together and the Traditional Lecture Method (TLM) on Iranian and Indian EFL/ESL undergraduate learners': (a) reading comprehension in English, (b) language learning strategies, (c) attitudes towards English language learning and the select teaching methods, and (d) retention of information. All these objectives were addressed with respect to different-level achievers of the target groups with the help of field studies and experiments in Iran and India. It should be mentioned that Learning Together or Cooperative Group-Based Learning (CGBL) method has been developed by Johnson and Johnson at the University of Minnesota in the USA.

It became evident from the analysis of the data gathered that CTBL and CGBL served to (a) increase acquisition of texts contents, (b) widen repertoire of language learning strategies, (c) generate positive attitudes, and (d) improve retention of information, on the part of the target groups more significantly than the TLM. (Hosseini, 2014) Further analysis of the data revealed that whereas CGBL was substantially more effective in developing the reading skills of the participants, CTBL was more successful in developing their metacognitive and affective strategies. It was likewise noted that CTBL facilitated the participants' long-term retention of information or their depth of understanding of the texts contents more effectively than CGBL. The results also indicated that it was CGBL, rather than CTBL, that was more successful in Iran. But, in India, it was CTBL.

In another study, this researcher (Hosseini, 2012b) found that CTBL contributed to the language proficiency of Iranian EFL college seniors more effectively than Structured Academic Controversy method of Johnson brothers at the University of Minnesota in the USA. Also in 2014, in another study, he compared the effectiveness of his method with Group Investigation, developed by Sharan and Sharan (1992) at Tel Avive University, in Israel, with reference to the language proficiency of Iranian EFL intermediate students. This researcher found that his method was more effective in promoting the language proficiency of Iranian EFL intermediate students.

In her study, Jahanbazian (2015) intended to look and compare the possible effects of CTBL with Learning Together (LT) - the most popular method of Cooperative Learning (CL) -- on oral performance of Iranian EFL intermediate students. She also wanted to measure the participants' attitudes towards language learning, individualistic class structure, CL, and the selected methods before and after the study. The results of the study showed that CTBL had a more significant effect on improving the oral performance of Iranian intermediate students. Analysis of the quantitative questionnaire results confirmed that there was more tendency towards supporting the implementation of cooperative strategies. More specifically, the participants had more positive attitudes towards CTBL rather than LT.

Akbarzadeh's (2016) study was an experimental investigation on the effects of CTBL and Student Teams Achievement Divisions (STAD), developed by Slavin and associates (1977) at Johns Hopkins University, in the US, on the reading comprehension of Iranian EFL intermediate students. After conducting an IELTS Reading test to a total population of 75, sixty students were selected, based on their scores in the pretest. Then they were randomly assigned to control and 
experimental groups - thirty per group. Each class was divided into seven teams of four - the two remained students in each class worked in pairs. The control group was instructed via STAD technique, which is a well-known technique of cooperative learning, while the experimental group were instructed via this researcher's approach to (language) teaching (i.e., CTBL). The reading comprehension test (posttest) was used at the end of the study to assess the probable progress in the reading comprehension ability of the students. The results of the study confirmed the significant effects of CTBL on the participants' reading comprehension achievement.

In another study, Salimi Bani (2017) studied the effect of CTBL and Cooperative Integrated Reading and Composition (CIRC) on the reading comprehension of Iranian intermediate EFL learners. She found significant results which proved the superiority of CTBL over CIRC in improving the reading comprehension of Iranian intermediate EFL learners.

And finally, Salari $(2018,2019)$ studied the effect of CTBL vs. Reciprocal Teaching of Reading (RTR) ), developed by Palinscar, at the University of Michigan, and Brown (1985), at the University of Illinois at Urbana-Champaign, on reading comprehension ability of Iranian EFL learners. She also tried to gage the attitude of the participants towards these methods before and after the study. In her study, after administering Interchange placement test to a total population of 75, and after ensuring that the participants were at the intermediate level and that they were homogenous, sixty students were selected, based on their scores in the pretest. Then, they were randomly assigned to two experimental groups - thirty per group. Each class was divided into seven teams of four - the two remaining students in each class worked in pairs. Before the experiment, we conducted the Interchange reading test and the questionnaire. In the course of experimentation, while the first experimental group was instructed via RTR method of CL, the second experimental group was instructed via this researcher's method of (language) teaching (i.e., CTBL). At the end of the study the questionnaire was applied once again. The reading comprehension test (posttest) was also used to assess the probable progress in the reading comprehension ability of the students. The results on independent samples T-test verified the significant impact of CTBL on the participants' reading comprehension achievements. That is, CTBL was more effective than RTR in improving the reading comprehension ability of Iranian EFL intermediate students. It was also found that the participants had developed more positive attitudes towards CTBL.

\section{CONCLusion AND Clousure}

The common belief is that language is a means for communication. But in his PhD thesis, in 2009, this researcher rebutted such a traditional definition. As explained, in his theory and hypothesis, this researcher has castigated the present theories and hypotheses in the field of ELT/Education and has gone beyond the red lines occasioned by imperialist and dictatorial Education regimes' theorists/think tanks. This researcher has done such in an attempt to formulate his beliefs about education into a systematic educational approach for overthrow of corrupt/dictatorial regimes thereby tackling the present eduo socio-economical and particularly political problems at local, national and international levels.

Contrary to the conventional instructional methods and approaches, the nature and the characteristics of this researcher's pedagogical innovation not only contribute to language learning (strategies) and excellence in the learning. They likewise promote true and flexible active learning, interactive competence, long-term retention, and especially the acquisition of some crucial habits of mind such as objectivity, and critical and creative thinking. Another outstanding feature of this world-class approach to ELT/Education refers to the fact that it facilitates tomorrow citizenry to instil humanitarian interpersonal skills and democratic values, principles, and norms which are essential requirements for successful life-long learning, working, interdependence, and survival in today world context. (Hosseini, 2011)

The importance of CTBL, as a fundamentally different approach to ELT/Education, thereby, goes beyond academic achievement of participants. That is what highly differentiates CTBL from the conventional methods and approaches lies in the fact that it focuses upon foundational facets of contemporary education by aiming at forming and moulding interdependent competent life-long learners who will be able to flourish both academically as well as socially. More particularly, the significance of CTBL for today world context refers to the fact that in addition to developing communication abilities and social skills of today students, it aims at empowering and turbo charging their minds in order to transform them into tomorrow's agents of change or the Subjects who will have the capacity to influence the world and contribute to more civilised social order/cohesion and eventually to world peace.

As a highly structured, psychologically and socio-politically based learning-centered strategic didactic approach, which mingles affective, cognitive and socio-political aspects of learning, CTBL is an exceptional edu-political approach that aims at awakening, empowering and emancipating the oppressed majority, who have been ignored and even belittled in the present world circumstances. As this researcher has explained in his weblog (Hosseini, 2011), considering its magic transforming power for converting today students/objects to agents of change or the subjects who have the capacity to influence the world, his inimitable revolutionary innovation is in essence a catalyst for change. CTBL, thereby, has been introduced to compensate the deficiencies of the present methods and innovations and reduce the discrepancy between what the present education system makes out of our nations and what the realities of today world context exacts them to be. (See Hosseini, 2014)

Competitive Team-Based Learning is the sum total of this researcher's academic life. As a major building block to modern democracy, CTBL derives inspirations from his philosophy. His CSPLL theory serves CTBL as an axis. His 
MIO hypothesis is the skeleton of CTBL. His especial evaluation system serves his approach to the education of the Oppressed as a heart. His educational materials, tasks, techniques, and activities shape its flesh. This researcher's ethos manifest in the form of his approach's spirit. And his objective and syllabus guides CTBL as its brain. CTBL is this researcher's vow: His vow against any sources of condescending look, Hitlerian outlook, oppression, corruption, destruction, and terror and bloodshed, at societal, social, and global level. CTBL's main mission is to unfold the real worth of despots after he awakens their soldiers and possessions - the people/ the feeble. This researcher will fight the battle against the despot, who plays the role of an oppressive god, to give meaning to his sufferings, and to heal his wounds occasioned by his special guard.

This researcher has brought himself, by long meditation, to the conviction that the dawn of CTBL connotes the demise of the remainders of the ancient barbarous despots/emperors in today world context as he strongly believes that the fate of empires depends on teachers' approaches to the education of the youth. CTBL, this researcher's realistic approach to liberal education is, thereby, in the last analysis though, an ensured pathway to human security, development, and prosperity all of which contribute to global peace, the ultimate dream of humanity in today world context of racism, injustice and despotism. CTBL is a future oriented edu-political approach which responds to the need for a paradigm shift in today world Education. It involves a shift in teaching paradigms, a shift in the way of thinking about teaching and living.

To sum up, the illocutionary force of this article is the implementation of this researcher's didactic weapon by teachers, in the present dog-eat-dog world context of racism, injustice and despotism, if they want to contribute to just societies and world peace. But for the perlocutionary effect of this article to come true, there is a need for the teachers, particularly in corrupt/dictatorial regimes, to have the courage to transform themselves first into intellectual sources of critical awareness and agents of change (change in cognition, thinking styles, beliefs, attitudes, and actions of the inhabitants of their milieus). This kind of transformation accelerates transforming of their students for uprooting any sources of corruption, oppression, fascism, terror and bloodshed, and destruction from among their societies. This way, they could ensure appropriate developments in their societies and consequently in the world. Hence the necessity of realising and the very need for redefining teaching as a complicated eduo-political process which involves democratic thinking - at the global level, and diplomatic acting - at the class level, if we want to contribute to world peace.

For more comprehensive understanding of CTBL, it's salient features, techniques, evaluation system, syllabus, materials, tasks and activities, and also for teachers as well as students responsibilities in classes run through CTBL, rationale beyond the success of CTBL, and much more information contact this researcher or see his $17^{\text {th }}$ seminal guidebook titled Competitive Team-Based Learning: Beyond Current Didactic Methods, which was published by Lambert Academic Publishing, Germany, in 2015/2018 (ISBN 978-613-9-88479-7). As this researcher has explicated (Hosseini, 2011), this seminal 676-page volume has special foci upon:

1. Penetrating deep into the conventional antediluvian dictatorial didactic regimes, which cherish the Banking Method, and excoriating the beyond;

2. Shedding light on the chronological development of language teaching methodology for justifying the need for accommodating Dr Hosseini's innovation in education regimes;

3. Engineering the conventional educational methods and approaches towards CTBL;

4. Differentiating CTBL from other innovative methods/approaches, and discussing the significance and relevance of this holistic approach against the backdrop of on-going globalisation which means a great deal of competitive spirit in today world context;

5. Bringing to the fore the author's Multiple Input-Output Hypothesis and Cognitive Socio-Political Language Learning Theory, which is the core of theoretical foundations of CTBL;

6. Implementing CTBL via the emerging online technologies state/country wide, and

7. Stimulating the readers' critical, analytical, and creative thinking skills, and promoting their personal growth especially through the 13 chapter-end thought-provoking discussion questions.

This invaluable resource manual, which introduces teaching as the heart of modern democracy, will be of immense help particularly to those educators who are committed to the cause of nation as well as peace building. As a gold mine of the latest issues in ELT/Education, it will also be found highly useful for ELT students, teachers of all subjects at all levels, and in-service programmes and seminars for instructors. Policy makers, educationalists, researchers, syllabus designers, and material developers could also take note of the noteworthy benefits this manuscript proposes. (Hosseini, 2011) You can download the first edition of this book for free from http://iranglobal.info/node/67290 or contact this researcher to send you the second edition of the book.

\section{SUGGESTIONS FOR FURTHER RESEARCH}

This researcher suggests theorists/specialists to compare his theory and hypothesis with the present theories/hypotheses from different angles. He also suggests language teachers and researchers at all grade levels to compare the effectiveness of his approach to (language) teaching with other methods and approaches with regard to all skills and sub skills of language. That way, they could help the authorities of foreign language learning and language teaching in ministries of education and science and technology make decisions about implementing CTBL in schools and universities. Furthermore, this researcher believes that CTBL has more significant impacts on the development of 
students' higher-quality cognitive/learning strategies and higher order of incisive, critical and analytical thinking skills such as abstract thinking and critical deductive reasoning. Also he is of the strong opinion that his innovative revolutionary approach to teaching, which focuses upon the implementation of systematic teamwork amidst competitive environments, contributes to tommorrow citisenries' objectivity, creativity, social skills, socio-political awareness and in the last analysis to nation building, more civilised societies, modern democracy and world peace more effectively than the present methods and approaches. These areas could be investigated by teachers/ researches in other fields of education also.

\section{REFERENCES}

[1] Akbarzadeh, M. (2016). A Study into the Effects of Competitive Team-Based Learning And 'Student Teams- Achievement Divisions' on The Reading Comprehension of Iranian EFL Intermediate Students. Unpublished MA Thesis, Islamic Azad University of Roudehen, Iran.

[2] Brown, A. L. (1984). Reciprocal teaching of comprehension-fostering and comprehension-monitoring activities. Cognition and Instruction, 1, 117-175.

[3] Ellis, R. (2003). Task-Based language learning and teaching. Oxford: Oxford University Press.

[4] Freire, P. (1973. Education for critical consciousness. New York: Continuum.

[5] Hosseini, S.M.H. (2000). The Impact of Competitive Team-Based Learning on the Reading Comprehension of Iranian High School Students. Unpublished MA Thesis, Islamic Azad University of Garmsar, Iran.

[6] Hosseini, S.M.H. (2007a). ELT in Higher Education in Iran and India: A Critical View. Language in India, 7, 1-11. Retrieved from http://www.languageinindia.com/dec2007/eltinindiaandiran.pdf (accessed on: 24/01/ 2019).

[7] Hosseini, S.M.H. (2007b). Infusion of Emerging Online Technologies into ELT: The Need of the Hour", Published at Perspectives in Education, 25(2009): 119-127. Also, [Online] Available at: http://eltweekly.com/2009/06/eltweekly-issue22research-paper-by-mohammad-hassan-hosseini/ (accessed on: 30/01/2019).

[8] Hosseini, S.M.H. (2009). Effectiveness of Cooperative Learning Methods: A Study with Iranian and Indian Undergraduate Learners. Unpublished PhD Thesis, Mysore University, India.

[9] Hosseini, S.M.H. (2010). Theoretical foundations of Competitive Team-Based Learning. Canadian International Journal of English Language Teaching 3, 229 - 243.

[10] doi:10.5539/elt.v3n3p229. Retrieved from http://www.ccsenet.org/journal/index.php/elt/article/view/7236 (accessed on: 24/01/ 2019).

[11] Hosseini, S.M.H. (2011). http://www.beyondelt.blogfa.com

[12] Hosseini, S.M.H. (2012a). Beyond the present methods and approaches to ELT/education: The crucial need for a radical reform. Tehran: Jungle Publication.

[13] Hosseini, S. M. H. (2012b). A study of the effects of Competitive Team-Based Learning and Structured Academic Controversy on the language proficiency of Iranian EFL college seniors. The International Journal of Adult Vocational Education and Technology, 3, 100-105. doi: 10.4018/javet.2012100105.

[14] Hosseini, S. M. H. (2014). Competitive Team-Based Learning versus Group Investigation with reference to the language proficiency of Iranian EFL intermediate students. International Journal of Instruction, 7, 176-188.

[15] Hosseini, S.M.H. (2015). Method Engineering: Towards a Strategic Approach to the Empowerment of the Other. International Journal of SYLWAN, 4(2),159-168.

[16] Hosseini, S.M.H. (2018). Competitive Team-Based Leaning: Beyond current didactic methods. Germany: Lambert Academic Publishing.

[17] Hosseini, S.M.H. (2019). Competitive Team-Based Learning vs. Reciprocal Teaching of Reading: A Study in Reading Classes. Journal of Language Teaching and Research, May Issue. Forthcoming.

[18] Jahanbazian, T. (2015). A study into the effects of 'Competitive Team-Based Learning' and 'Learning Together' on the oral performance of intermediate EFL Learners. Iranian Journal of Research in English Language Teaching, 3, 60-73. Retrieved from http://relp.khuisf.ac.ir/article_533624_3a87dbba748748e68ba1f08bc20cd106.pdf (accessed on: 24/01/ 2019).

[19] Jahanbazian, T. (2015 b). A Study into the Effects of Competitive Team-Based Learning and Learning Together on the Oral Performance of Intermediate EFL Learners. Unpublished MA Thesis, Kohgiloyeh And Boyer Ahmad Islamic Azad University, Iran.

[20] Jahanbazian, T. (2015). Competitive team-based learning in conversation classes. Germany: Scholar Press.

[21] Jiang, Y. (2010). A feasibility study of applying "double-output hypothesis" into task-based teaching approach in second language acquisition. Language Teaching and Research, 1, 397-400. doi: 10.4304/jltr.1.4.397-400.

[22] Krashen, S. D. (1985). The input hypothesis: Issues and implications. London: Longmont.

[23] Long, M. H. (1996). The role of the linguistic environment in second language acquisition. In W. C. Ritchie \& T. K. Bhatia (Eds.), Hand book of second language acquisition (pp. 413-468). San Diego, CA: Academic Press.

[24] Salari, F. (2018). The Effect of Competitive Team-Based vs. Reciprocal Program in Reading Comprehension Ability of Iranian EFL Learners. Unpublished MA Thesis, Quchan Islamic Azad University, Iran.

[25] Salimi Bani, K. (2017). The Effect of Competitive Team-Based Learning (CTBL) and Cooperative Integrated Reading and Composition (CIRC) on the Reading Comprehension of Iranian Intermediate EFL Learners. Unpublished MA Thesis, Khorasgan (Isfahan) Islamic Azad University, Iran.

[26] Schmidt, R. (2001). Attention. In P. Robinson (Ed.), Cognition and second language instruction. New York: Cambridge University Press.

[27] Slavin, R. E. (1978). Student teams and achievement divisions. Journal of Research and Development in Education, 12, 39-49.

[28] Stern, H. H. (1992). Issues and options in language teaching. Oxford: Oxford University Press.

[29] Swain, M. (1993). The output hypothesis: Just speaking and writing aren't enough. The Canadian Modern Language Review, 50, 158-164. doi: 10.3138/cmlr.50.1.158. 


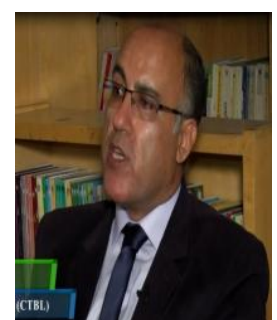

Seyed Mohammad Hassan Hosseini, as an Iranian liberal educator, is interested in democratic education and has a zest for awakening, empowering, and emancipating the oppressed majority. He succeeded to publish more than 150 bookticles during his stay in India, in the course of pursuing his PhD, in ELT. Dr Hosseini has suggested language as a liberating agent in his seminal Cognitive Socio-Political Language Learning Theory based upon which he introduced his instructional weapon, a weapon for the overthrow of dictatorial regimes. Particularly, he recalibrates the critical attitude of his mind towards the philosophy beyond curricula in corrupt regimes and focuses upon the importance of his didactic weapon for educators in today world context of tyranny. Although Dr Hosseini has the experience of teaching in different universities both in Iran and overseas, he has been obliged to teach at a school for backward students in Mashhad. Dr Hosseini is now searching for a job in another country. 